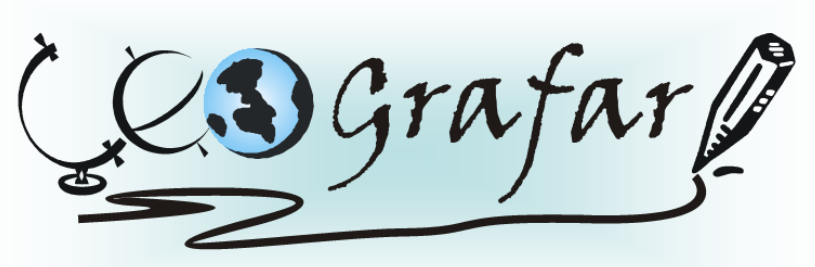

Revista Eletrônica do Programa de Pós-Graduação em Geografia - UFPR

\title{
A CONSTRUÇÃO DE MAPAS SOCIAIS PARA O RECONHECIMENTO DOS PROBLEMAS AMBIENTAIS E A BUSCA DA QUALIDADE DE VIDA DA COMUNIDADE DA PRAIA DAS FONTES, BEBERIBE - CEARÁ
}

\author{
THE CONSTRUCTION OF SOCIAL MAPS FOR RECOGNITION OF \\ ENVIRONMENTAL PROBLEMS AND SEARCH OF LIFE QUALITY FOR THE \\ PRAIA DAS FONTES COMMUNITY, BEBERIBE - CEARÁ
}

Ana Nery Amaro Evangelista Mestranda em Geografia Universidade Federal do Ceará Fortaleza, CE, Brasil e-mail: ananeryevangelista@yahoo.com.br

Nicolly Santos Leite Doutoranda em Geografia Universidade Federal do Ceará

Fortaleza, CE, Brasil e-mail: nicollyleite2@gmail.com

Mônica Merle Filgueiras de Souza Profa. Rede Municipal de Beberibe

Fortaleza, CE, Brasil e-mail: ecomonica@yahoo.com.br

Adryane Gorayeb Prof ${ }^{a}$. Dr $\stackrel{a}{\text {. }}$ do Departamento de Geografia Universidade Federal do Ceará

Fortaleza, CE, Brasil e-mail: gorayeb@ufc.br

\section{RESUMO}

A comunidade tradicional pesqueira da Praia das Fontes está localizada no município de Beberibe, litoral leste do Ceará, possui um modo de vida que associa valorização e conhecimento dos aspectos ambientais às práticas econômicas locais, como a pesca tradicional, artesanato, pequenos comércios e atividades ligadas ao turismo. No território ocupado por essa população verificam-se ambientes naturais atualmente valorizados pela sociedade, como riachos, fontes de água doce, campo de dunas, praia e falésias de areias coloridas que atraem elevado fluxo turístico 
acompanhado da expansão imobiliária, causando problemáticas socioambientais. Deste modo, pretende-se discutir a utilização das técnicas e produtos cartográficos como ferramentas de uso social para a garantia do território diante das pressões vivenciadas. Nesse sentido, realizaram-se encontros com os moradores da Praia das Fontes visando promover o mapeamento social do território e das áreas de pesca. A partir das reuniões foi possível refletir as demandas e os desafios da comunidade, e, assim, fortalecer o processo de articulação comunitária e construir um produto cartográfico voltado para a reinvindicação de direitos sociais junto aos órgãos públicos. Destaca-se que tal iniciativa aproximou sociedade e academia, cumprindo o papel social da universidade e contribuindo para o fomento da conservação da natureza e da cultura tradicional comunitária.

Palavras-chave: Cartografia Social. Comunidades Tradicionais. Problemas Ambientais.

\section{ABSTRACT}

The traditional fishing community of Praia das Fontes is located in Beberibe, east coast of Ceará. It has a way of life that combines appreciation of environmental issues to local economic practices, such as traditional fishing, craft, small businesses and activities related to tourism. The territory occupied by this population shows natural environments currently valued by society, such as streams, freshwater sources, dune field, beach and cliffs of colored sands that attract high tourist flow accompanied by the housing boom, causing environmental problems. Thus, we intend to discuss the use of techniques and cartographic products as social use tools to guarantee the territory in the face of experienced pressures. In this regard, meetings were held with residents of Praia das Fontes to promote the social mapping of the territory and fishing areas. From the meeting it was possible to reflect the demands and challenges of the community, strengthen the process of community liaison and build a cartographic product aimed at the revindication of social rights with public agencies. It is noteworthy that this initiative came society and academia, fulfilling the social role of the university and contributing to the promotion of the conservation of nature and traditional community culture.

Keywords: Social Cartography; Traditional communities; Environmental Problems.

\section{INTRODUÇÃO}

Ao longo da história das sociedades percebe-se que os ideais de progresso humano estiveram ligados com a ideia de desenvolvimento, no entanto, o termo desenvolvimento foi considerado, em muitos casos, simplesmente a partir da capacidade produtiva, no qual os recursos eram tidos como ilimitados e o progresso humano deveria ser infinito, alcançado a qualquer custo. Percebe-se, contudo, a impossibilidade de armazenar infinitamente os resíduos originados pelas produções humanas no planeta e da mesma maneira não existem recursos inesgotáveis, que 
se perpetuem ou se renovem com rapidez para atender as necessidades de consumo dos seres humanos (RODRIGUEZ; SILVA, 2013).

Percebe-se que comunidades tradicionais pesqueiras que habitam o litoral cearense vêm enfrentando diversos desafios inerentes ao desenvolvimento de atividades econômicas localmente desordenadas, que se apropriam dos recursos e ambientes naturais sem, contudo, preocupar-se com os conhecimentos tradicionais acerca do território e a conservação de espaços que sustentam o modo de vida das populações locais. De modo geral, sobressai-se a atividade turística, a grilagem e venda de terrenos para a construção de segundas residências e mais, atualmente, tem-se focado, também, nos influxos negativos decorrentes da instalação de parques de energia eólica.

De acordo com o decreto no 6.040, de 7 de fevereiro de 2007, que instituiu a Política Nacional de Desenvolvimento Sustentável dos Povos e Comunidades Tradicionais - PNPCT, podemos considerar que povos e comunidades tradicionais são grupos culturalmente diferenciados, que assim se reconhecem e que ocupam permanentemente ou temporariamente (dependendo do grupo) determinado território considerado tradicional e que por meio dos conhecimentos e das práticas criadas e transmitidas pelos ancestrais, pela tradição, fazem usos de tal espaço e dos recursos naturais existentes para a manutenção e reprodução da cultura, da religiosidade, das atividades sociais, econômicas e ancestrais (BRASIL, 2007).

Neste sentido, busca-se realizar uma discussão acerca das problemáticas inerentes ao turismo vivenciadas pela comunidade da Praia das Fontes, localizada no município de Beberibe, que vive da pesca artesanal e busca resistir à privatização dos espaços comuns, em razão de um turismo desenfreado sobre os termos de seu território de uso tradicional. Enfoca-se as atividades de cartografia social realizadas junto aos moradores da comunidade tradicional pesqueira, a fim de representar temas relevantes, através da participação ativa e conjunta da comunidade e da universidade, tendo como objetivo gerar instrumentos que contribuam na manutenção dos territórios, das tradições, dos direitos e na busca por qualidade de vida para os povos tradicionais contemplados.

A grande produtividade das atividades humanas, baseada em um desenvolvimento apenas econômico, aliado a falta de consciência crítica, ao não questionamento acerca das consequências de tais pensamentos e práticas, 
fomentaram impactos degradantes e crescentes ao meio ambiente (DÍAZ, 2002). O modelo de desenvolvimento brasileiro está baseado na lógica do sistema capitalista, que propaga a compressão tempo-espaço e uma globalização dos mercados capaz de promover a homogeneização de todo o planeta, mas, na verdade, o que ocorre é o aumento da desigualdade entre as nações, sentida também localmente (SANTOS, 2011).

De acordo com Diegues (1999), o território brasileiro experimenta historicamente um desenvolvimento predatório que gerou e ainda, atualmente, tem suscitado a degradação das formas de uso tradicionais, que não se enquadram no modelo capitalista dominante, como sociedades tribais, camponesas ou pesqueiras, mas que mantém e prezam a interação com a natureza, sendo estas comunidades tradicionais também responsáveis pela conservação da biodiversidade.

Assim, as desigualdades, o comprometimento dos recursos naturais, a especulação e exploração dos espaços são impasses principalmente enfrentados pelas populações mais pobres e também pelas comunidades tradicionais, pois conservam relações diversas (renda e subsistência, lazer, atividades culturais etc.) com os recursos existentes nos espaços tradicionalmente habitados, que também lidam com a apropriação dos territórios por atividades como o turismo "que tem no espaço geográfico seu principal objeto de consumo" (CRUZ, 2003).

Em relação às comunidades tradicionais pesqueiras localizadas no litoral cearense, percebe-se que, em muitos casos, que é o turismo predatório o principal agente modificador das dinâmicas socioambientais e das estruturas presentes localmente. No polo turístico do estado do Ceará, por exemplo, a má implementação da atividade turística tem gerado diversos problemas de caráter ambiental, além de problemas sociais, como a descaracterização das culturas, problemas com as drogas e com a prostituição (CORIOLANO, 1996). Ainda em relação aos impactos causados pelo turismo nas praias do litoral cearense Coriolano (1996, p.95), evidência alguns fatos ocorrido:

Em Flecheiras, praia do município de Trairi, foram realizados aterros de mangues para construção de uma estrada e de um hotel com objetivos turísticos. Em Balbino, outra localidade praiana, foram realizadas compras de pés de coco dispersos, como única forma de acesso à apropriação da terra dos nativos. No Morro Branco e na Praia das Fontes, no litoral leste do Estado, foram feitos desmontes de falésias e terraplanagem de morros, acidentes geográficos que serviam de guias aos pescadores que voltavam 
desorientados de alto mar, por não possuírem bússola. Na praia das Fontes acabou-se o acesso fácil dos pescadores à praia, pois a construção de uma hotel cinco estrelas, com seus chalés, levou a entrada da praia para bem distante [...]. Em Caponga ocorre o assoreamento e a poluição do rio Mal cozinhado, em consequência da construção do hotel dos franceses às suas margens. Em Jericoacoara, a poluição da praia decorre dos dejetos e coliformes fecais e quantidade de visitantes que chegam ao mesmo tempo.

As problemáticas associadas ao turismo, todavia, não são as únicas responsáveis por perturbações no litoral cearense. A implantação de parques eólicos também sustentam, contraditoriamente, problemáticas socioambientais, e apesar do amplo discurso sustentado sobre a energia eólica como uma alternativa de "energia limpa", observa-se que são implantados em áreas ambientalmente frágeis, alterando os ambientes e artificializando a paisagem, além de ocuparem territórios tradicionais com promessas de empregos, o que na realidade não se efetiva, tendo em vista que tais empreendimentos necessitam de mão-de-obra especializada (MENDES, et al. 2015).

A partir de análise sobre os impactos socioambientais dos parques de energia eólica na comunidade de Xavier, município de Camocim, no litoral oeste do Ceará, Mendes et al. (2015) relatou diversas dificuldades enfrentadas pela comunidade após a instalação do empreendimento, destaca-se a dificuldade de acesso da população de Xavier à áreas de uso tradicional e à outras comunidades próximas, em virtude da privatização da principal área de circulação pelo parque eólico. Os autores também expõem que a população local já presenciou a explosão de hélices dos aerogeradores, o que os deixa em constante alerta.

Pode-se dizer que as comunidades tradicionais, todavia, são detentoras de conhecimentos culturais e dos aspectos da dinâmica ambiental dos territórios que vivem demonstrando capacidade de promover um desenvolvimento econômico local aliado à conservação ambiental e cultural, sendo, portanto, exemplos de que é possível utilizar a natureza sem inviabilizar sua capacidade de suporte. No entanto, no caso das comunidades tradicionais pesqueiras que habitam o litoral cearense é preciso superar os desafios impostos pelo avanço de capital de maneira desigual, excludente e degradante.

É necessário promover alternativas que possibilitem o empoderamento dos povos, instrumentalizando-os para a manutenção e fortalecimento da cultura/identidade, dos meios de vida e de seus territórios, a fim de revindicarem e 
garantirem a conservação das múltiplas atividades implementadas em tais espaços, e possibilitando uma melhor qualidade de vida para as populações.

Nestas perspectivas, considera-se que o processo de cartografia social pode desempenhar importante função no sentido de legitimação territorial e fortalecimento político da comunidade, transpondo em mapas os anseios e os problemas enfrentados, identificando e registrando os conflitos, os recursos naturais, os usos e vivências no território (GORAYEB; MEIRELES, SILVA, 2015; LIMA; COSTA, 2012).

Os mapas participativos construídos, integram um conjunto de características inerentes à linguagem cartográfica, obedecendo regras e normas que os qualificam cientificamente, constituindo-se, assim, em uma linguagem válida, universal (GORAYEB; MEIRELES, SILVA, 2015) e de fácil compreensão pela população em geral e órgãos públicos. No Brasil, verificam-se que práticas de mapeamento social têm sido desenvolvidos amplamente, destacando-se as práticas do projeto Nova Cartografia Social com povos da Amazônia, que apresenta diversas publicações, como livros, fascículos, artigos (ALMEIDA, 2008; ALMEIDA, 2009; ALMEIDA; SANTOS, 2009); e as experiências em comunidades urbanas e tradicionais no Ceará (GORAYEB; MEIRELES, SILVA, 2015).

Existem no Brasil algumas terminologias que remontam aos trabalhos realizados de mapeamento com a participação das populações locais como "cartografia social", "mapeamento comunitário participativo", "mapeamentos culturais", "etnomapeamento", dentre outros, mas vale ressaltar, que diante destas e outras terminologias empregadas as metodologias e estratégias de trabalho podem variar (CORREIA, 2007 apud ACSELRAD; COLI, 2008).

Tais atividades tiveram início em âmbito nacional a partir da década de 1990 com a participação de diferentes populações e comunidades (reserva extrativista, terras indígenas, populações que ocupavam terras há gerações, etc.) que habitam a região de alcance do Programa Grande Carajás (extração mineral), onde foram identificados os diversos conflitos existentes, posteriormente, em 2004, o projeto Nova Cartografia Social da Amazônia desenvolve diversas atividades de capacitação com comunidades voltadas ao entendimento das técnicas cartográficas, a fim de realizar um mapeamento acerca das problemáticas sociais, econômicas e ecológicas enfrentadas pelos grupos envolvidos, já em âmbito internacional, vale 
destacar, que as iniciativas deram-se a partir da década de 1960 no Canadá e no Alasca (ACSELRAD; COLI, 2008).

De acordo com Colchester (2002 apud ACSELRAD; COLI 2008, p. 19) "o mapeamento pode ajudar a trazer coerência para o seio da comunidade e reafirmar o valor e a relevância do conhecimento tradicional ao infundir respeito pelos anciãos e pelas práticas tradicionais de manejo dos recursos". Assim, os trabalhos de mapeamento que levem em consideração a experiência e os conhecimentos das comunidades envolvidas podem contribuir de maneira significativa para 0 fortalecimento e mobilização das mesmas, através da promoção de encontros, debates e a reflexão acerca de assuntos relativos à conjuntura vivida, e para a garantia, controle e organização dos territórios tradicionalmente habitados, permitindo a manutenção das práticas culturais, religiosas, sociais, econômicas, inerentes ao modo de vida tradicional e, consequentemente, uma melhor qualidade de vida para tais populações.

A comunidade litorânea da Praia das Fontes é um povoado urbano que se situa no município de Beberibe, localizado no litoral leste do estado do Ceará, estando no litoral do município de Beberibe a 79 km de Fortaleza (Figura 1).

Situando-se próxima da sede do município, a Praia das Fontes está localizada entre a Praia de Morro Branco e a Praia do Diogo. Conforme a Secretaria Municipal de Assistência a Saúde de Beberibe, Praia das Fontes possui população total em 2011 de 448 habitantes, constitui-se em um dos destinos mais procurados por turistas devido à beleza cênica de suas paisagens marcadas pela presença de campo de dunas móveis e fixas e falésias com águas ressurgentes, e lagoas, como a lagoa interdunar da Uberaba.

No contexto de riquezas naturais, a praia possui paisagens naturais (Figura 2), com a presença de falésias, feição geomorfológica mais representativa deste trecho da costa do estado. As falésias neste setor formam labirintos, grutas, além de ressurgências hídricas. Outros ambientes naturais de destaque são campos de dunas fixas e móveis atualmente ocupados por parques de energia eólica, mas que também se comportam como importantes reservatórios hídricos superficiais e subterrâneos, em razão da sua constituição sedimentar que permite a infiltração e armazenamento de água. 

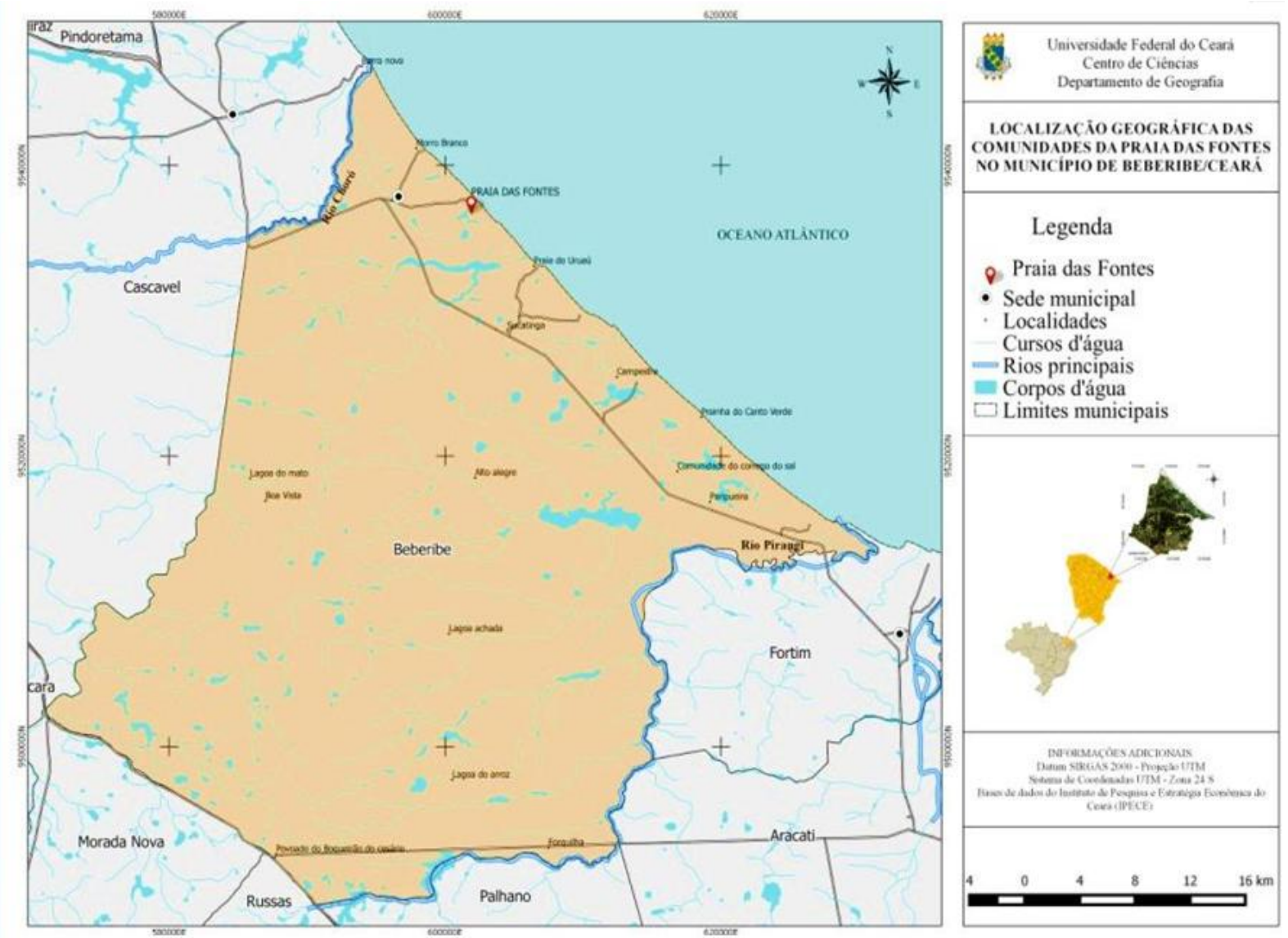

Figura 1 - Mapa da localização geográfica da Praia das Fontes- Beberibe/CE. Fonte: Leite (2016).

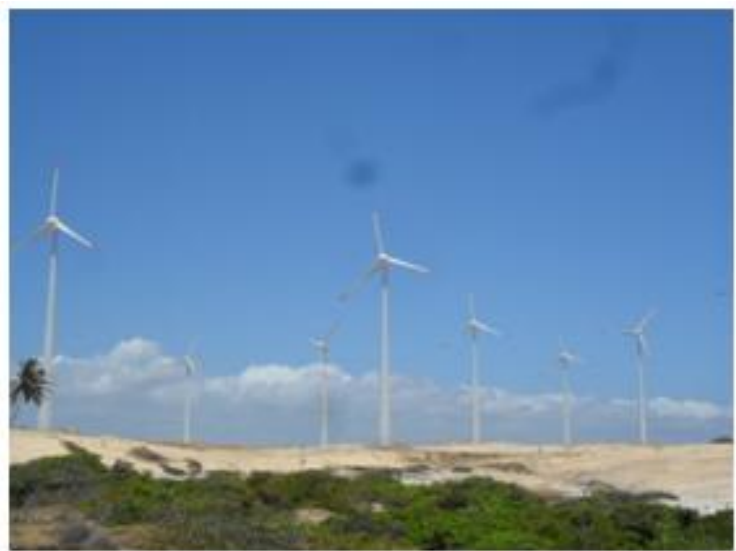

Figura 02: Campo de dunas ocupado por aerogeradores de energia eólica. Fonte: Evangelista (2013).

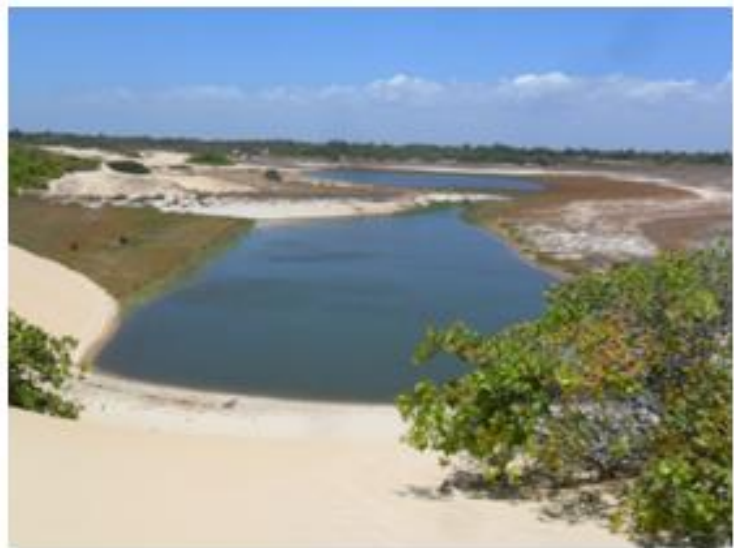

Figura 03: Lagoa interdunar da Uberaba. Fonte: Evangelista (2013).

Em relação às fontes hídricas, também chamadas de "correntes" pelos moradores, que são pequenos riachos de origem dunar, que cortam a comunidade $e$ chegam à praia com águas cristalinas, são utilizados em múltiplos usos, como lazer, limpeza (lavagem de roupas e utensílios domésticos), dessedentação animal e no 
abastecimento humano, como a lagoa interdunar na Uberaba (Figura 3), responsável, também, pelo abastecimento público de água às residências no município. O próprio nome da comunidade faz menção à diversidade dos recursos hídricos.

A prerrogativa da construção do mapa social da comunidade litorânea da Praia das Fontes surgiu por meio de demanda da comunidade durante a execução do projeto de pesquisa "Cartografia social e manejo de bacias hidrográficas: estudos, práticas e conhecimento tradicional para a construção de novas realidades socioambientais", que está vinculado ao Laboratório de Geoprocessamento (LABOCART) do curso de Geografia, da Universidade Federal do Ceará (UFC) e contou com financiamento da Fundação Cearense de Apoio ao Desenvolvimento Científico e Tecnológico - FUNCAP. No decorrer do projeto foram identificadas, por intermédio da visão Geossistêmica, os aspectos naturais e socioeconômicos da citada comunidade e verificou-se que a probabilidade de se praticar uma gestão adequada do território, era sobremaneira difícil, uma vez que a comunidade possui abundancia de recursos naturais, e que estes recursos estão sendo apropriados de maneira arbitrária por interesses alheios ao bem comum da comunidade.

A fim de garantir a preservação dos aspectos culturais, naturais e do modo de vida tradicional da comunidade, realizou-se uma parceria entre moradores e universidade, a partir da realização de atividades voltadas à construção de mapas sociais.

\section{MÉTODO}

A metodologia para a construção do mapa ocorreu da seguinte forma: (i) encontro para apresentação da cartografia social e diagnóstico das pretensões da comunidade em relação aos mapas (Figura 5); (ii) reuniões participativas para a construção de mapas, com a elaboração de overlays (Figura 6); (iii) transposição das informações do papel (overlay) ao Sistema de Informação Geográfica - SIG (software QGIS); (iv) revisão e validação dos mapas (Figura 7) entrega dos mapas junto à comunidade da Praia das Fontes (Figura 8).

O primeiro encontro que aconteceu na comunidade reuniu vinte cinco moradores e cinco estudantes. Foram debatidas as problemáticas vivenciadas e 
elencados os anseios da comunidade elegendo-se os aspectos que seriam evidenciados durantes a construção do mapa social.

O encontro posterior foi efetivamente de elaboração dos mapas, onde, foram disponibilizadas à comunidade imagens do software Google Earth, impressas em papel A3, destacando a comunidade e o mar, com buffers criados de dez em dez quilômetros. Através da sobreposição de folhas de papel vegetal, e com o uso de canetinhas, a comunidade desenhou e formou a legenda, com as orientações dos estudantes, contendo representações do passado, do presente e proposições para 0 futuro (o que foi, o que é, e o que gostariam que fosse).

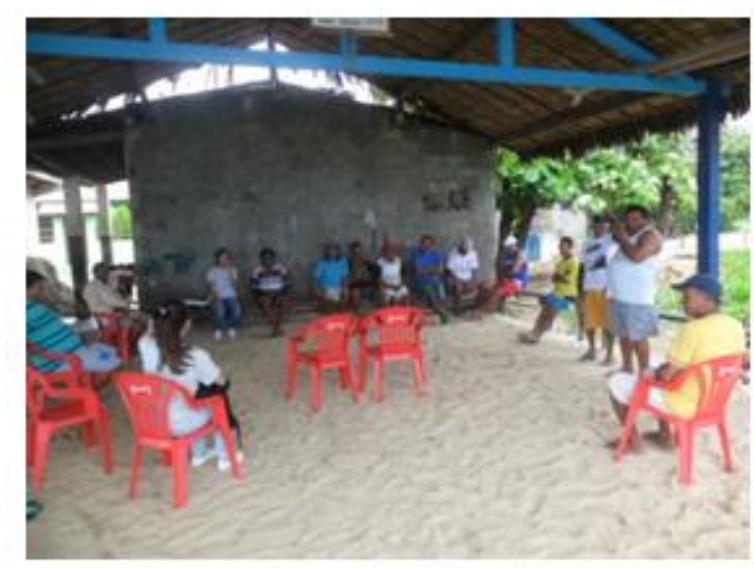

Figura 5 - Reunião com os pescadores e moradores da comunidade da Praia das Fontes. Fonte: Landim (2013)

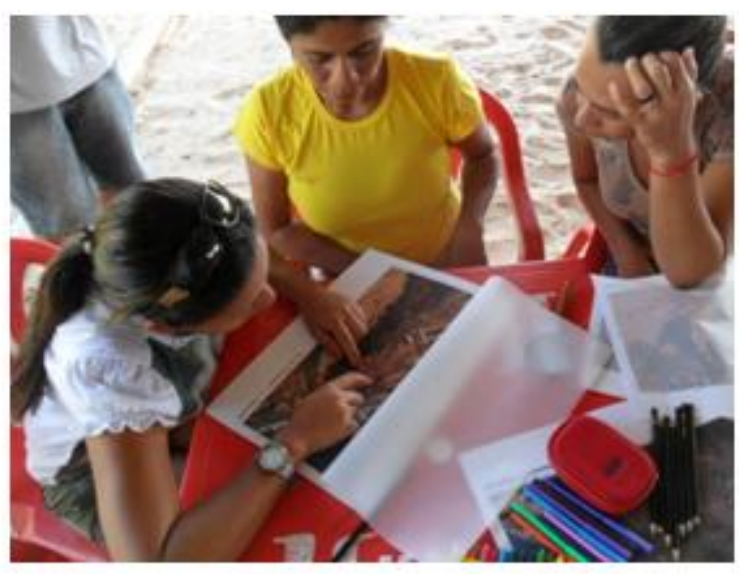

Figura 6 - Elaboração dos mapas sociais na comunidade da Praia das Fontes. Fonte: Leite (2013)

Posteriormente, as representações, das formas e das legendas, foram levadas ao Laboratório de Geoprocessamento (Labocart) pela equipe de estudantes responsável pelo projeto, onde foram transcritas para uma versão digital, por meio do software livre e aberto QGIS na versão 2.0. Ressalta-se, que ao transpor as informações levou-se em consideração a fidelidade às representações.

A versão preliminar do mapa, contendo as informações construídas pelas pessoas da comunidade foi levada, em terceiro momento, para a comunidade que realizou novas considerações e, posteriormente, foram feitas as alterações necessárias. 


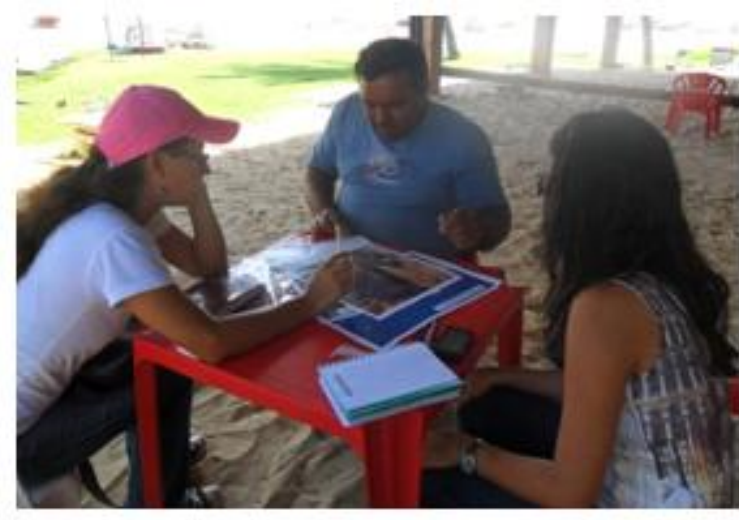

Figura 7 - Revisão do mapa com líder da colônia de pescadores. Fonte: Freitas (2014)

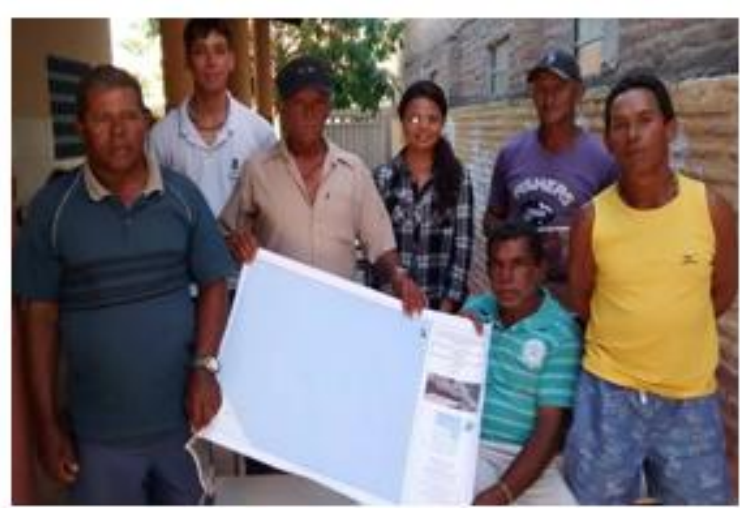

Figura 8 - Entrega do mapa de pesca à comunidade da Praia das Fontes. Fonte: Freitas (2014)

A entrega do mapa de pesca à comunidade aconteceu em uma linda festa organizada pela escola (Figura 9) com apresentações culturais pelos estudantes do Ensino Fundamental.

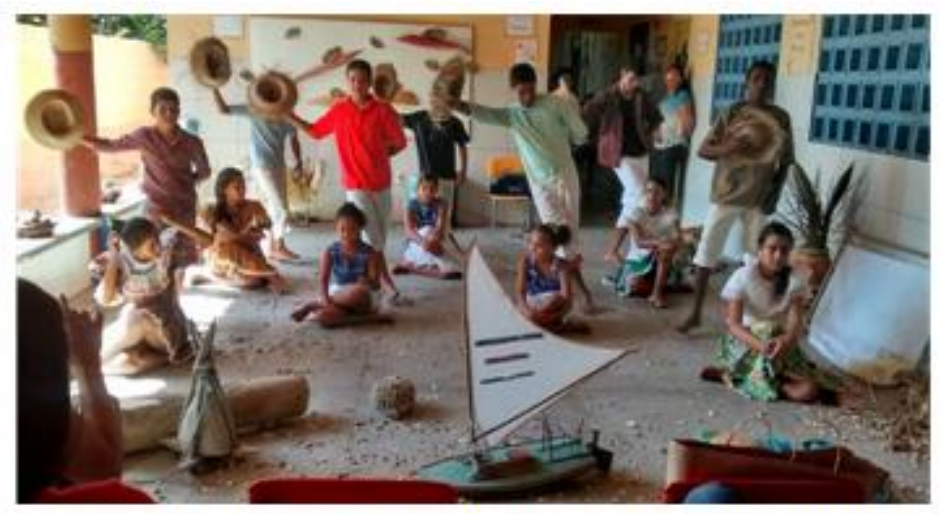

Figura 9 - Apresentação cultural de estudantes da Praia das Fontes na cerimônia de entrega do mapa social. Fonte: Gorayeb (2014)

\section{RESULTADOS E DISCUSSÕES}

Foram construídos mapas sobre a pesca, os quais mostram a questão da pesca e suas problemáticas, sendo marcados no mapa os pontos de pesca em quilômetros e em graus em relação à praia, e as espécies capturadas nesses locais. Também foram elaborados mapas onde foram projetadas as problemáticas vivenciadas pela comunidade. No geral, neste mapa foram evidenciadas a construção de grandes empreendimentos, barracas e restaurantes que aproximam- 
se do núcleo de ocupação e áreas comuns representativas, "encurralando" a comunidade e grilando suas terras.

Por conta das belezas naturais, uma série de fatores coloca em risco a integridade social da comunidade. Grandes resorts e hotéis se instalaram, ocupando de forma desordenada grande parte das terras, além do fato de parques eólicos também terem se instalado no campo de dunas. Ademais, também foram relatados problemas relacionados à pesca tradicional, como a falta de estrutura pesqueira e a diminuição do pescado, no decorrer dos anos.

Os moradores praticam a pesca artesanal a bordo de jangadas, que são pequenos barcos a vela. Entretanto, este setor do litoral está sendo bastante explorado pela pesca em escala industrial, muitas vezes de origem externa ao estado e ao país, que utiliza equipamentos que capturam de forma indiscriminada ou mesmo predatória dos recursos marinhos, gerando conflitos e dificultando a vida dos pescadores locais.

Para melhor compreensão, cita-se a instalação de um hotel local, em que o proprietário construiu um muro que separa a comunidade do campo de dunas e de nascentes utilizadas há décadas pelos nativos, de forma totalmente arbitrária e indevida. O terreno foi cercado para que os poços que foram cavados para abastecer a grande infraestrutura do hotel não fossem "prejudicados pelos moradores", o que traz muitos transtornos à comunidade, isolando-a do campo de dunas que dá acesso à lagoa dunar da Uberaba. Algo que também se interpõe neste percurso é a mega infraestrutura dos aerogeradores monitorados vinte e quatro horas por sistema de vigilância eletrônica e seguranças motorizados, que fazem a rota para impedir o acesso das pessoas às proximidades das torres de energia eólica.

Pretende-se continuar contribuindo para a luta da comunidade na garantia de seu território e costumes tradicionais, através de pedido junto à prefeitura de Beberibe de uma audiência pública para que possa ser debatida entre a comunidade e legisladores a situação dos moradores da Praia das Fontes.

A partir do processo de cartografia social realizado, foi possível promover a difusão da informação, das tecnologias da comunicação, e através desses instrumentos a comunidade que outrora sentia-se injustiçada, pode se articular e 
refletir a problemática vivenciada e, assim, colocar em debate as questões socioambientais enfrentadas pelas comunidades tradicionais no litoral do Ceará.

\section{CONCLUSÃO}

A experiência nos denota que a gestão do território é, a cada dia que passa, algo que deve ser mais debatido entre população e governantes. Os atos legislativos, muitas vezes, estão desvinculados erroneamente da realidade palpável da sociedade. A simplificação dos problemas sociais é algo que está sendo colocado em cheque, prioritariamente os governantes precisam conhecer de forma mais aprofundada a vida, no sentido da ordem social, dos cidadãos.

Sabemos que essa discussão é muito mais complexa do que a simples informação, pois a garantia dos direitos sociais, a propriedade privada e a posse da terra são as principais causas de conflitos que estão relacionados com o egoísmo desmesurado do ser humano, que na ânsia de retirar vantagens, apropria-se da terra e dificulta sobremaneira a vida daqueles que dela necessitam para sobreviver a partir de atividades tradicionais, na forma da agricultura, pecuária, pesca e extrativismo.

Entender a complexidade da organização da vida das pessoas em sociedade é uma tarefa difícil de ser executada, principalmente na atualidade em que cada vez mais, o sentido da globalização tende a estender seus valores baseados no consumo a qualquer custo e homogeneizar em âmbito global, as formas de expressões culturais.

Neste sentido, a cartografia social tem o papel de promover o debate comunitário e servir como um dos modelos alternativos possíveis, de caráter sólido, pois propicia a exposição e o manuseio do instrumento construído a partir da iniciativa participativa e popular (o mapa, modelo em 3D, etc.) para contrapor as injúrias sofridas e lutar contra o poder hegemônico das forças dominantes do capital de grandes empresas nacionais e internacionais.

Porém, entendemos que cada comunidade decide pela criação do mapa por causa de demandas específicas e que arraigados a cada grupo existem também divergências e conflitos de ordem interna, e que o instrumento cartográfico não pode ser o curador de todas as problemáticas, mas propicia um processo rico de trocas de 
conhecimentos entre as pessoas, e é também um elemento de inclusão social, uma vez que, durante os mapeamentos participam crianças, jovens, adultos e anciãos, cada indivíduo sendo respeitado de acordo com sua capacidade cognitiva e sua visão de mundo.

$\mathrm{Na}$ perspectiva da inclusão dentro dos pilares da cidadania, os trabalhos desenvolvidos na comunidade tradicional pesqueira da Praia das Fontes vêm contribuindo na promoção do desenvolvimento acadêmico e também social, a partir da troca de conhecimentos científicos e tradicionais, que propiciam a garantia de direitos e o desenvolvimento dos povos e comunidades tradicionais, entendendo que o conhecimento é fruto de construção coletiva e é direito de toda a sociedade.

É válido ressaltar o papel das agencias financiadoras para o desenvolvimento das pesquisas científicas, aqui rendemos um agradecimento especial à Fundação Cearense de Apoio ao Desenvolvimento Científico e Tecnológico - FUNCAP, pela ajuda no financiamento desta e de outras pesquisas.

\section{Referências}

ACSELRAD, Henri. (Org.). Cartografias sociais e território. Rio de Janeiro: Universidade Federal do Rio de Janeiro, Instituto de Pesquisa e Planejamento Urbano e Regional, 2008.

ACSELRAD, H.; COLI, L. R. Disputas territoriais e disputas cartográficas. In: ACSELRAD, H. (Org.). Cartografias sociais e território. Rio de Janeiro: Universidade Federal do Rio de Janeiro, Instituto de Pesquisa e Planejamento Urbano e Regional, 2008. p. 13-43.

ALMEIDA, A. W. B. de. (Org.). Antropologia dos Archivos da Amazônia. Rio de Janeiro: Casa 8, Fundação Universidade do Amazonas, 2008. Disponível em: < http://novacartografiasocial.com/livros/colecao-nova-cartografia-social/>. Acesso: 15. fev. 2016.

ALMEIDA, A. W. B. de. (Org.). Conflitos sociais no "Complexo Madeira". Manaus: Projeto Nova Cartografia Social da Amazônia, UEA Edições, 2009. Disponível em: < http://novacartografiasocial.com/livros/colecao-nova-cartografia-social/>. Acesso: 17. fev. 2016.

ALMEIDA, A. W. B. de.; SANTOS, G. S. do. (Org.). Estigmatização e território: mapeamento situacional dos indígenas em Manaus. Manaus: Projeto Nova Cartografia Social da Amazônia, Editora da Universidade federal do Amazonas, 
2009. Disponível em: < http://novacartografiasocial.com/livros/colecao-novacartografia-social/>. Acesso: 15. fev. 2016.

BRASIL, Decreto no 6.040, de 7 de fevereiro de 2007. Institui a Política Nacional de Desenvolvimento Sustentável dos Povos e Comunidades Tradicionais. Diário Oficial da República Federativa do Brasil, Brasília, DF, 7 fev. 2007. Disponível em: http://www.planalto.gov.br/ccivil_03/_ato2007-2010/2007/decreto/d6040.htm. Acesso em: 10 nov. 2013.

BRASIL, Governo Federal, Ministério do Meio Ambiente. Resolução CONAMA $357 / 2005$.

CORIOLANO, Luzia Neide M. T. Turismo e degradação ambiental no litoral do eará. In: LEMOS, Amalia Ines (Org.) Turismo e Impactos Sócio-ambientais, São Paulo, Hucitec, 1996.

CRUZ, Rita de Cássia Ariza da. Introdução à geografia do Turismo. 2. ed. São Paulo: Roca, 2003.

DIEGUES, A. C. S. Biodiversidade e comunidades tradicionais no Brasil. São Paulo: MMA, 1999. Disponível em: < http://www.mma.gov.br/estruturas/chm/_arquivos/saberes.pdf>. Acesso em: 18 fev. 2016.

GORAYEB, A.; ANDRADE, A. J. de.; SILVA, E.V. da. (Org.). Cartografia social e cidadania: experiências de mapeamento participativo dos territórios de comunidades urbanas e tradicionais. Fortaleza: Expressão Gráfica Editora, 2015.

LIMA, M. V. da C.; COSTA, S. M. G. da. Cartografia social das crianças e adolescentes ribeirinhas/quilombolas da Amazônia. Geografares, no 12, p. 76- 113, 2012. Edição Especial. Disponível em: <http://novacartografiasocial.com/artigos/>. Acesso: 20 mar. 2016.

MENDES, J. de S.; GORAYEB, A.; MEIRELES, A. J. de A.; SILVA, E. V. da. Impactos socioambientais em comunidades atingidas pelos empreendimentos de energia eólica: o caso de Xavier, Camocim, Ceará. In: GORAYEB, A.; ANDRADE, A. J. de.; SILVA, E.V. da. (Org.). Cartografia social e cidadania: experiências de mapeamento participativo dos territórios de comunidades urbanas e tradicionais. Fortaleza: Expressão Gráfica Editora, 2015. p. 135-149.

RODRIGUEZ, José Manuel Mateo. Educação Ambiental e Desenvolvimento Sustentável: Problemática, Tendências e Desafios. Fortaleza: Edições UFC, 2013.

SANTOS, Milton. Por uma outra globalização: do pensamento único à consciência universal. Rio de Janeiro: BestBolso, 2011. 